\title{
Using behavioural theory to understand adherence to behaviours that reduce transmission of COVID-19; evidence from the CHARIS representative national study
}

\author{
Diane Dixon*I (D, Chantal Den Daas', Gill Hubbard ${ }^{2}$ and \\ Marie Johnston'
}

\author{
'Aberdeen Health Psychology Group, Institute of Applied Health Sciences, University \\ of Aberdeen, UK \\ ${ }^{2}$ Department of Nursing, School of Health, Social Care and Life Sciences, University of \\ the Highlands and Islands, Inverness, UK
}

Objectives. To examine the ability of four models of behaviour, namely, Protection Motivation Theory (PMT), the Common Sense Self-Regulation Model (CS-SRM), and Social Cognitive Theory and the Reasoned Action Approach (SCT and RAA) to understand adherence to transmission-reducing behaviours (TRBs) advised by national governments for suppression of SARS-CoV2.

Design. A series of six cross-sectional telephone surveys of a random representative sample of adults living in Scotland.

Methods. Self-reported adherence to three TRBs (physical distancing, wearing a face covering and handwashing), PMT, CS-SRM, and SCT/RAA constructs, and sociodemographic variables were measured each week for 6 weeks $(n=\sim 500 \mathrm{p} / \mathrm{w}$; third June-15th July) via a 15 min telephone survey.

Results. Adherence was high ('Always' or 'Most times') throughout for physical distancing and handwashing, and, when mandated, for wearing a face covering. Older people were more adherent to all TRBs. Constructs from all three models predicted all three TRBs. Intention and self-efficacy (SCT/RAA) were the only beliefs to predict to all three TRBs each week and for all groups equally; intention was the strongest predictor. The predictive utility of PMT and CS-SRM varied by TRB and by group. Of note was the observation that several illness beliefs were associated with adherence only for those who believed they had not had COVID-I9.

Conclusions. The CHARIS project has identified beliefs about specific behaviours, the illness and the risks associated with lower adherence rates that might be addressed in national interventions. It confirms previous findings that some groups show lower levels of adherence and might be specially targeted.

This is an open access article under the terms of the Creative Commons Attribution-NonCommercial-NoDerivs License, which permits use and distribution in any medium, provided the original work is properly cited, the use is non-commercial and no modifications or adaptations are made.

*Correspondence should be addressed to Diane Dixon, Aberdeen Health Psychology Group, Institute of Applied Health Sciences, School of Medicine, Medical Sciences and Nutrition, Rm I I4, Health Sciences Building, Foresterhill, Aberdeen AB25 2ZD, UK (email: diane.dixon@abdn.ac.uk). 


\section{Statement of contribution}

What is already known?

- Physical distancing, hand hygiene and wearing a face covering reduce the transmission of coronavirus SARS-CoV-2.

- But, adherence to these behaviours is not consistent.

- Adherence varies by sociodemographic groups and by behaviour type.

- Our understanding of what predicts adherence in general and between different groups is limited.

\section{What does this study add?}

- CHARIS has shown that beliefs about the behaviours are the most consistent predictors of adherence.

- Self-efficacy and intention predicted adherence to each behaviour in each sociodemographic group.

- The predictive utility of risk and illness beliefs varied across behaviours and between groups.

\section{Background}

The COVID-19 pandemic has highlighted the importance of behavioural science in the control of infectious disease. West, Michie, Rubin, and Amlôt (2020) have identified the many points at which behaviour could prevent transmission of the virus ranging from physical distancing to avoiding face touching and governments have developed advice, guidelines and laws to persuade, encourage, enable or coerce transmission-reducing behaviours (TRBs; Michie et al., 2020; West et al., 2020). Even though effective vaccines are now available, adherence to TRBs is still required and vaccine uptake may also be influenced by behavioural factors (Borthwick, O'Connor, \& Kennedy, 2020; Corace et al., 2016) and interventions can be directed at the determinants of these behaviours, cementing the alliance between biological, epidemiological, clinical, and behavioural sciences in preventing and managing infectious disease.

Epidemiological modelling estimated the effect of measures to reduce transmission of the coronavirus on COVID-19 mortality (Alagoz, Sethi, Patterson, Churpek, \& Safdar, 2020; Ferguson, Laydon, \& Nedjati-Gilani, 2020; Jewell, Lewnard, \& Jewell, 2020). Based on these epidemiological models, it was clear that people's adherence to transmission reducing behaviours (TRBs), such as physical distancing (e.g., maintaining a 2 m distance between self and others when in public), wearing a face covering, handwashing, and 'staying a home' is vital in reducing disease transmission. Empirical work has validated the modelling studies, for example, in the United States counties with a 'stay-at-home' order reported lower COVID-19 case rates 10, 20, and 30 days after the enactment of the 'stay-athome' order (Lyu \& Wehby, 2020) and in an international study of 149 countries there was clear evidence of reduced prevalence of COVID-19 following introduction of behavioural restrictions (Islam et al., 2020).

This body of epidemiological research shows that adherence to TRBs is of critical importance to reducing the spread of the coronavirus and resulting COVID-19. The need to maintain adherence to TRBs is not negated by the recent availability of effective vaccines. Rather, adherence to TRBs will be of central importance during the vaccination programme and will be required until such time as the general population is fully vaccinated. Indeed, the recent re-introduction of strict lockdown measures across all four nations of the UK is illustration of the need for improved adherence to TRBs now a new and more easily transmissible variant of the virus has emerged and become dominant within the UK (Kirby, 2021). 


\section{Adherence to TRBs}

International evidence, including in the UK, suggests that on the whole, adherence to TRBs is high among the general population but there are temporal variation and differences by type of TRB and demographic characteristics (Belot et al., 2020; Duffy, 2020; Fancourt, Bu, Wan Mak, \& Steptoe, 2020; Ipsos Mori, 2020; Park et al., 2020; YouGov, 2020). Adherence is higher in some sociodemographic groups than others. For example, older people are more adherent than younger people (Coroiu, Moran, Campbell, \& Geller, 2020; Masters et al., 2020; Pedersen \& Favero, 2020). However, knowing who is more or less adherent only allows one to predict the behaviour, but not to explain why it might occur and, while it indicates which groups it might be important to target in interventions to enhance adherence, it gives no indication of the processes than might be addressed by the intervention (Johnston, 2015). It is therefore important to gain some understanding, not only of who is less adherent, but which behavioural processes might explain non-adherence.

Adherence to physical distancing behaviours during the COVID-19 pandemic was associated with other health-protective behaviours at a geographical level: USA counties with more adherence to limiting travel also show healthier behaviours as evidence by obesity, physical activity, and flu vaccination rates (Bourassa, Sbarra, Caspi, \& Moffitt, 2020). There is ample evidence of psychological predictors of adherence behaviours based on a variety of theoretical frameworks. For example, based on personality theories, physical distancing was found to be associated with personality traits including psychopathy and empathy (Carvalho \& Machado, 2020). Recent empirical evidence is compatible with the COM-B model in predicting adherence: health literacy (capability; Coroiu et al., 2020), compensation schemes for loss of income due to quarantine (opportunity; Bodas \& Peleg, 2020), fear of COVID-19 (Harper, Satchell, Fido, \& Latzman, 2020), and conspiracy beliefs (Freeman et al., 2020; motivation) are predictive of adherence to TBRs. A survey of 2025 UK adults found that all three COM-B components significantly predicted good hygienic practices (e.g., washing hands with soap and water), with motivation having the greatest influence on behaviour (Gibson Miller et al., 2020).

\section{Theory and adherence to COVID-19 TRBs}

Given the primacy of motivation in understanding adherence to TRBs, studies that draw on theories of human motivation and behaviour are likely to provide most explanatory power. Theories which have been adopted in explaining motivation to adhere to preventive and protective behaviours and which also indicate possible opportunities for intervention to enhance adherence address three main types of beliefs: beliefs about behaviour, beliefs about the disease threat and beliefs about risk. Each type of theory has been related to adherence to COVID-19 preventive and precautionary TRBs.

First, many theories explain behaviour, including health-related behaviour, usually incorporating beliefs in perceived control over the behaviour and about the value of the outcomes of the behaviour. Two of the main theories are Social Cognitive Theory (SCT; Bandura, 1986, 2001; Cameron, Fleszar-Pavlovic, \& Khachikian, 2020) and the Reasoned Action Approach (RAA; and its predecessors the Theory of Planned Behaviour and the Theory of Reasoned Action; Azjen \& Schmidt, 2020; Fishbein \& Ajzen, 2011) both of which include those two constructs, as self-efficacy plus outcome expectancies and attitudes, respectively, and both have been successful in predicting behaviour and proposing targets for interventions. Using these theories, Bogg and Milad (2020) found 
that adherence to TRB guidelines was associated with attitudes, self-efficacy, subjective norms, and intentions (Bogg \& Milad, 2020).

Second, the main theory which explains behaviour in terms of beliefs about illness is Leventhal's Common-Sense Self-Regulation Model (CS-SRM; Cameron et al., 2020; Leventhal, Meyer, Nerenz, \& Rachman, 1980; Leventhal, Nerenz, \& Steele, 1984). The beliefs about illness that are central to the model are as follows: beliefs about the nature (identity), time-course (timeline), personal impact (consequences), causal factors (cause), and feasibility of control or cure (control/cure) of the illness. Perceived consequences, timeline, and emotional representations have been found to be related to various TRBs in studies of Greek and Swedish samples (Papakosma, 2020).

The third type of model addresses beliefs about risk and the main model is Protection Motivation Theory (PMT) which incorporates beliefs about the risk associated with the disease and the efficacy of responses including adherence behaviours (Orbell, Zahid, \& Henderson, 2020; Rogers, 1975). Using PMT, threat and coping appraisals were associated with intention to adhere to COVID-19 TRBs in hospital staff (Bashirian et al., 2020) and response efficacy and self-efficacy with physical distancing intentions in students (Haque, Karim, Kabir, \& Tarofder, 2020). Other studies have examined the relationship of risk perception to COVID-19 TRBs; for example, perception of personal risk was related to TRBs in the early stages of COVID-19 in the USA (Wise, Zbozinek, Michelini, Hagan, \& Mobbs, 2020) and Australia (Faasse \& Newby, 2020).

\section{The CHARIS project: COVID-19 health and adherence research in Scotland}

The aims of CHARIS are to examine rates of adherence to government advised or mandated TRBs and theoretical predictors of adherence to these TRBs. To achieve this aim CHARIS conducts weekly cross-sectional surveys of representative samples of the population of Scotland and uses constructs from SCT/RAA, CS-SRM and PMT to predict and understand adherence generally and in particular groups. The study began in the week following the first release from strict lockdown by the Scottish Government (which required the population to stay at home except for essential purposes). Here, we report the first 6 weeks of transition through the first and second phases of release from lockdown.

\section{Research questions}

1. How did adherence change over time for three behaviours; keeping $2 \mathrm{~m}$ distance from other people; wearing a face covering; and regular handwashing?

2. Who adheres? Which sociodemographic variables are associated with adherence to each behaviour?

3. Which variables from each of the theories (SCT, RAA, CS-SRM, and PMT) were associated with adherence to each behaviour?

\section{Methods}

\section{Design}

Weekly cross-sectional, telephone surveys of a representative sample of the population of Scotland for 6 weeks from 3rd June to 15th July 2020. Scottish Government phases (https://www.gov.scot/coronavirus-covid-19/) and key dates were as follows: May 28th: 
Lockdown move to Phase 1; June 18th: Phase 1 move to Phase 2; June 22nd: Face coverings became mandatory on public transport; July 9th: Phase 2 move to Phase 3; July 10th: Face coverings became mandatory in shops.

\section{Participants and recruitment}

Approximately 500 adults participated each week, which was the sample size required to enable a representative sample. Adult men and women aged 16 or older, able to speak English, and currently living in Scotland were eligible to participate. The survey was administered by a commercial polling company (Ipsos MORI Scotland), who conducted telephone interviews using computer-aided telephone interviewing (CATI), which involves random digit dialling to both landlines and targeted mobiles. Data collection took place between place between 9 am-9 pm on weekdays and 10 am-7 pm on weekends. Quotas were applied to ensure a representative sample of Scotland adults was achieved. Quotas were based on gender, age, working status, and geographical locations (distribution over the Scottish Parliament regions).

\section{Measures}

\section{Adherence}

Adherence to each behaviour was assessed as follows:

Physical distancing was assessed using one behaviour: staying $2 \mathrm{~m}$ ( 6 feet) away from other people. Wearing a face covering was assessed in relation to two environments: wearing a face covering when in a shop and when travelling on public transport. Handwashing was assessed with four behaviours: washing hands as soon as you get home; washing hands using soap and water; washing hands for at least $20 \mathrm{~s}$ and washing hands before eating and drinking.

Participants indicated the extent to which they had adhered to each behaviour over the previous week using a 5-point response scale (always [5], most times [4], sometimes [3], rarely [2], and never [1]). The aggregate adherence score for face coverings and handwashing was the mean score across the two face covering items and the four handwashing items. A higher score indicates greater adherence.

\section{Theory-based beliefs}

CHARIS measured three different types of beliefs relevant to the transmission of coronavirus from the three theories; beliefs about the behaviours (SCT/RAA; self-efficacy and intention towards each behaviour; beliefs about the illness COVID-19 (CS-SRM; beliefs about the cause of COVID-19, its symptoms, the consequences of COVID-19 for the individual, whether it can be treated or cured, and how long the illness will last and the emotional representation of the illness) and beliefs about the risk and threat of coronavirus (PMT; beliefs about severity, risk, response efficacy, and response self-efficacy). Full details of the belief measures are provided in the Supplementary File (Table S1).

\section{Sociodemographic and clinical characteristics}

The sociodemographic characteristics assessed: age, gender, ethnicity, employment status, geographical region, Scottish Index of Multiple Deprivation (SIMD, which is the 
Scottish Government's standard area-based measure of deprivation. SIMD divides the country into 6,976 data zones and assigns a deprivation score to each based on seven domains: income, employment, education, health, access to services, crime, and housing), number in household, number of children in household, housing tenure, whether they believed they had had COVID-19 (regardless of whether or not they had had a confirmatory test) and whether they had been designated to be shielded due to other health conditions.

\section{Survey development}

A draft version of the survey was developed by the core research group (DD, GH, MJ and CDD), based on previous research and then shared with the CHARIS-consortium (a wider group of behavioural and health scientists drawn from Universities and Research Institutes across Scotland), and two patient and public involvement groups (the Scottish Health Council (SHC) Public Engagement Group and the NHS Research Scotland Primary Care Patient and Public Involvement group [NRSPC-PPI]). The draft survey was modified based on the feedback received to ensure question wording was clear and easily understood. Further, Ipsos Mori- piloted the survey and wording for measures was modified based on feedback.

\section{Statistical analysis}

Analyses were carried out using SPSS and R by one of the core research group (CDD). Univariate and multivariate analyses were undertaken. The significance level was set at a value of $p \leq .01$ throughout (we selected this more stringent $p$-value because we were not able to predict the number of analysis before starting them, as we only carried out moderation analyses for the relevant sociodemographic variables, therefore, we apriori chose the more stringent $p$-value of .01). Descriptive graphs show mean levels of adherence for each TRB at each data wave. Multivariate linear regression analyses were used to identify the demographic characteristics that predicted adherence to each TRB and to identify the beliefs within each theory that predict adherence to each TRB. Moderation analyses were used to examine the ability of those sociodemographic factors, shown to be predictive of adherence, to moderate the relationship between predictive beliefs and adherence to TRBs. For the moderation analysis, in a first step, a sociodemographic variable was combined with one of the moderator belief variables to assess the effect on adherence. In the second step of the regression analyses, the interaction term between the moderator and the sociodemographic variable was entered. The variables were not centred prior to producing the interaction terms, as the main concern was with the interaction term, and the interaction does not change whether you centre or not (Hayes, 2017). For the analyses, a 95\% bias-corrected percentile bootstrapped confidence interval method was used, and 5,000 bootstrap re-samples were produced for moderation examination. Additionally, we employed conventional methods for plotting simple slopes to understand moderation effects, at one standard deviation below and above the mean (Aiken, West, \& Reno, 1991).

The number of participants is not the same for all outcomes. This is because some outcomes were not applicable for all participants (people for example did not always leave their house in the previous week so items pertaining to behaviour when outside the home were not applicable). Analyses only include people for whom the behaviour was applicable. Adherence to physical distancing had 229 missing values, adherence to 
wearing face covering 552, and handwashing zero (it is an average on four items and only one item had the possibility of being not applicable).

\section{Results}

\section{Sociodemographic characteristics of participants}

In total 2,969 participants completed the survey over the 6 weeks from week 1 (3rd June) to week 6 (15th July 2020); the sociodemographic characteristic of the sample is shown in Table 1.

\section{Adherence and sociodemographics}

Adherence to physical distancing and hand hygiene behaviours was high throughout and showed no change over the 6 weeks. Use of face coverings increased from a mean adherence score of 2.19 (SD 1.67) to 4.07 ( $S D$ 1.4) between week 1 and week 6 ( $F(1$, $2,415) 289.9, p \leq 0.001$ ) with the significant increase occurring between weeks 3 and 4 (17th-30th June) which coincided with the wearing of face coverings on public transport being made mandatory (see Figure 1).

Results of simple regressions and full details of multivariable regressions are presented in the Supplementary File (Table S2).

In multivariable regression of sociodemographic variables, adherence to staying $2 \mathrm{~m}$ distant was associated with older age, and not having had COVID-19 $(F(24,2,712)=5.19$, $\left.p<.001, R^{2}=0.044\right)$. Adherence to wearing face covering was associated with older age, not working full-time, and home tenure $(F(24,2,394)=4.546, p<.001$, $\left.R^{2}=0.044\right)$. Adherence to handwashing was associated with being female, older age and having children in the household $\left(F(24,2,912)=6.214, p<.001, R^{2}=0.049\right)$.

\section{Adherence and theory-based beliefs}

Table 2 shows the results of the regression analyses for each behaviour and each theory.

Beliefs about the behaviour: SCT and RAA theories

Using the variables from SCT, both self-efficacy and intention predicted each of the behaviours. In multiple regression, both variables were predictive of each of the three behaviours. Intention was the strongest predictor of all three behaviours.

The addition of behavioural norm, as a key additional variable in the RAA, increased the prediction of adherence to wearing face coverings. As can be seen from Table 2, higher behavioural norm was associated with reduced adherence to wearing a face covering. Behavioural norm was not predictive of either physical distancing or handwashing.

Beliefs about illness: CS-SRM theory

CS-SRM variables were predictive for each behaviour. In multiple regression, physical distancing was predicted by timeline, cause, and emotional representation. Wearing face coverings were predicted by consequences, timeline, causes, and emotional representation. Handwashing was predicted by timeline and cause. 
Table I. Characteristics of people who participated in the CHARIS study $(N=2,969)$

\begin{tabular}{|c|c|c|c|}
\hline & $N$ & $\%$ achieved $^{a}$ & $\begin{array}{l}\% \text { required for } \\
\text { representativeness }\end{array}$ \\
\hline \multicolumn{4}{|l|}{ Age (in years) } \\
\hline \multicolumn{4}{|l|}{ Median, IQR } \\
\hline \multicolumn{4}{|l|}{ Age category (in years) } \\
\hline $16-24$ & 273 & 9.2 & 12 \\
\hline $25-34$ & 385 & 13.0 & 16 \\
\hline $35-44$ & 360 & 12.1 & 15 \\
\hline $45-54$ & 540 & 18.2 & 17 \\
\hline $55-64$ & 607 & 20.4 & 16 \\
\hline $65+$ & 804 & 27.1 & 23 \\
\hline \multicolumn{4}{|l|}{ Gender ${ }^{c}$} \\
\hline Male & 1,198 & 40.4 & 48 \\
\hline Female & $\mathrm{I}, 765$ & 59.6 & 52 \\
\hline \multicolumn{4}{|l|}{ Scottish Index of multiple deprivation ${ }^{c, d}$} \\
\hline I (10\% most deprived) & 133 & 5.4 & \\
\hline 2 & 176 & 6.7 & \\
\hline 3 & 198 & 7.6 & \\
\hline 4 & 216 & 8.2 & \\
\hline 5 & 244 & 9.3 & \\
\hline 6 & 297 & 11.3 & \\
\hline 7 & 317 & 12.1 & \\
\hline 8 & 348 & 13.3 & \\
\hline 9 & 341 & 13.0 & \\
\hline 10 (10\% least deprived) & 352 & 13.4 & \\
\hline \multicolumn{4}{|l|}{ Relationship status } \\
\hline Married/Living together & $\mathrm{I}, 524$ & 62.1 & \\
\hline Single/Widowed/Divorced/Separated & 927 & 37.9 & \\
\hline \multicolumn{4}{|l|}{ Geographyc } \\
\hline Lothian & 442 & 15.0 & 15 \\
\hline North East Scotland & 401 & 13.6 & 14 \\
\hline Glasgow & 327 & II.I & 13 \\
\hline West Scotland & 365 & 12.4 & 13 \\
\hline South Scotland & 397 & 13.4 & 13 \\
\hline Central Scotland & 385 & 13.0 & 12 \\
\hline Mid-Scotland and Fife & 364 & 12.3 & 12 \\
\hline Highlands and Islands & 274 & 9.3 & 8 \\
\hline \multicolumn{4}{|l|}{ Ethnicity $^{c}$} \\
\hline White & 2,865 & 97.4 & \\
\hline Non-white & 74 & 2.5 & \\
\hline \multicolumn{4}{|l|}{ Work status ${ }^{c}$} \\
\hline Working full time & 1,333 & 45.0 & 42 \\
\hline Not working full time & 1,632 & 55.0 & 58 \\
\hline \multicolumn{4}{|l|}{ No adults in the Household (incl self) ${ }^{c}$} \\
\hline 1 & 627 & 21.2 & \\
\hline 2 & 1,323 & 44.7 & \\
\hline 3 & 598 & 50.2 & \\
\hline$\geq 4$ & 413 & 13.9 & \\
\hline
\end{tabular}


Table I. (Continued)

\begin{tabular}{|c|c|c|c|}
\hline & $N$ & $\%$ achieved $^{\mathrm{a}}$ & $\begin{array}{l}\% \text { required for } \\
\text { representativeness }\end{array}$ \\
\hline \multicolumn{4}{|c|}{ Children $\left(\leq 16\right.$ years) in the household ${ }^{c}$} \\
\hline No & 2,418 & 81.5 & \\
\hline Yes & 549 & 18.5 & \\
\hline \multicolumn{4}{|l|}{ Housing tenure } \\
\hline Homeowner & 2,332 & 78.5 & \\
\hline Renter & 426 & 14.3 & \\
\hline Other/Don't know & 211 & 7.1 & \\
\hline \multicolumn{4}{|l|}{ Shielded by Govt ${ }^{\mathrm{c}}$} \\
\hline Yes & 349 & 11.9 & \\
\hline No & 2,592 & 88.1 & \\
\hline
\end{tabular}

a Valid per cent.; ${ }^{\mathrm{b}}$ Representativeness was assessed against four criteria; gender, age, working status and Scottish Parliament regions. Data are the quotas required for representativeness and are presented here to enable comparison against the sample achieved.; 'Missing: Gender $(N=6)$, Geography $(N=14)$, Ethnicity $(N=29)$, Work status $(N=4)$, Number of adults $(N=8)$, Number of children $(N=2)$, and Shielded $(N=28)$.; 'SIMD: Scotland is split into 6,976 data zones of approximately equal population size ( 760 people). Indicators of seven different domains (income, employment, health, education, housing, access to services and crime) are assessed in each zone, which are then ranked; $I$ is the most deprived zone. Data are presented by SIMD decile.
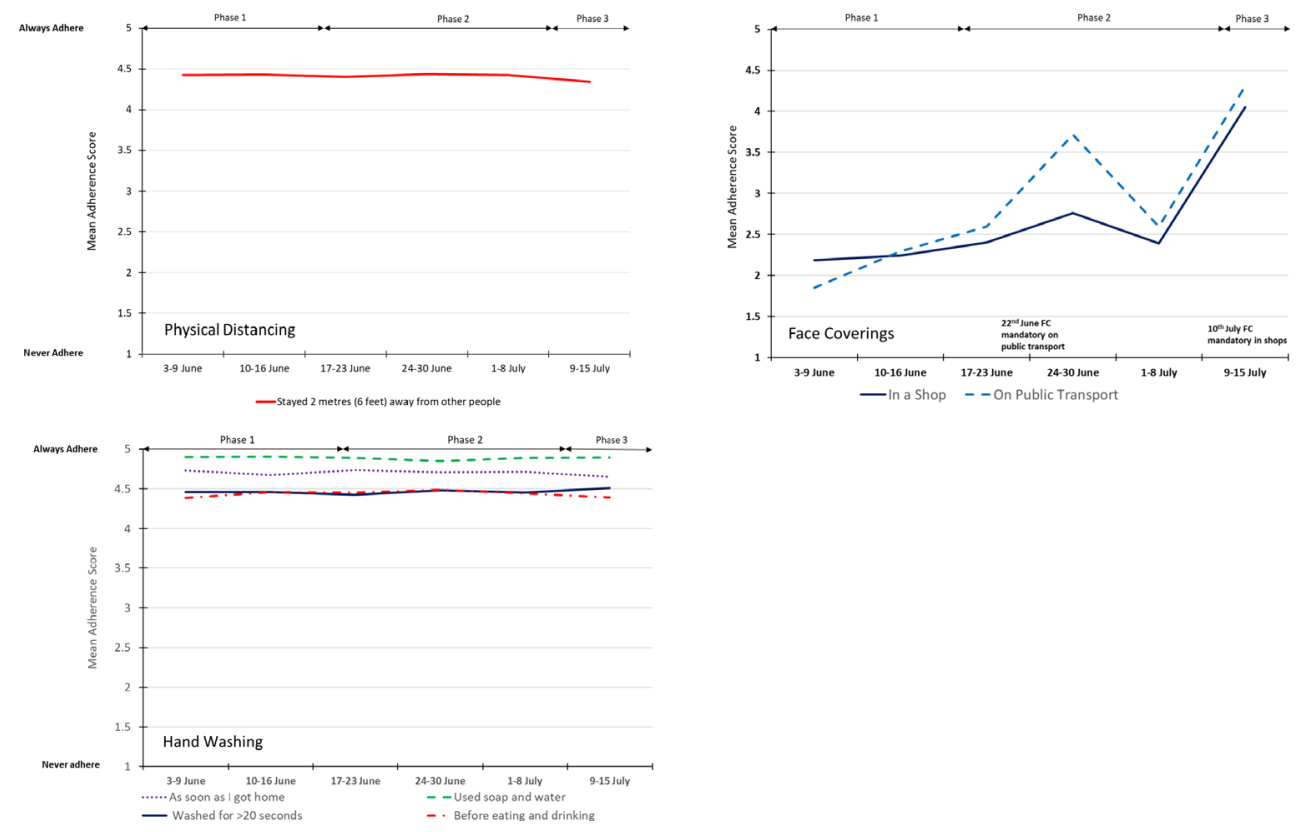

Figure I. Average adherence over time for each TRB. 


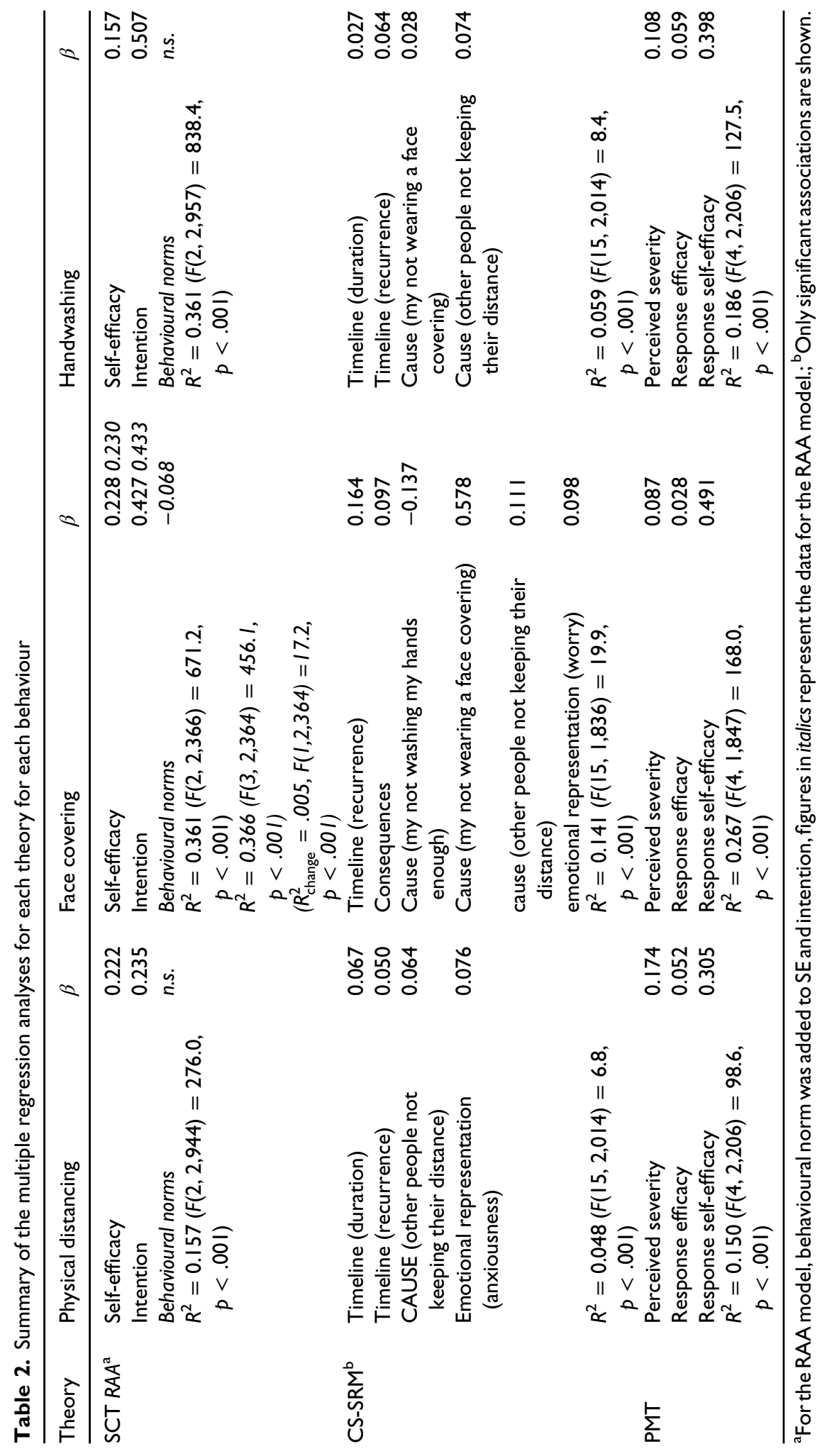


Beliefs about risk: PMT theory

Three PMT variables, namely perceived severity, response efficacy and response selfefficacy were predictive in univariate analyses of all three behaviours; perceived risk was not predictive. In multivariate analyses, all three beliefs remained predictive of each of the three behaviours. Response self-efficacy was the strongest predictor of each behaviour.

\section{Are the relationships between beliefs and adherence moderated by sociodemographic factors?}

A summary of the moderation analyses is provided in Table 3.

\section{Beliefs about the behaviour: SCT and RAA theories}

Sociodemographic factors did not moderate any of the relationships between SCT or RAA based beliefs and any of the TRBs.

\section{Beliefs about illness: CS-SRM theory}

As indicated in Table 2 numerous beliefs and emotional representations from the CS-SRM predicted all three behaviours. However, only five of those relationships were moderated by sociodemographic factors and only one sociodemographic factor acted as a moderator, namely perceived COVID-19 status.

Perceived COVID-19 status moderated only one of the four significant CS-SRM variables - physical distancing relationships. For those who believed they had not had COVID-19, the belief that COVID-19 is caused by other people not keeping $2 \mathrm{~m}$ distance predicted increased adherence to physical distancing, but was not predictive for those who believed they had already had COVID-19 $\left(\Delta R_{\text {interaction }}^{2}=.0066, F(1,2,635)=17.85\right.$, $p<.001$; unstandardized simple slope for COVID-19 negatives $=.16 \quad(p<.001)$; unstandardized simple slope for COVID-19 positives $=-.01$ (n.s.)).

Similarly, only one of the six significant CS-SRM - face covering relationships were moderated. Perceived COVID-19 status moderated the relationship between the amount of time spent worrying about COVID-19 (emotional representation) and wearing a face covering $\left(\Delta R_{\text {interaction }}^{2}=.0031, F(1,2,139)=7.42, p<.01\right)$. Worry predicted adherence for both groups but the relationship between worry and adherence to wearing a face covering was stronger for those who believed they had already had COVID-19 (unstandardized simple slope for COVID negatives $=.21(p<.001)$; unstandardized simple slope for COVID positives $=.45(p<.001)$.

In contrast, three of the four significant CS-SRM - handwashing relationships were moderated by perceived COVID-19 status. The belief that the symptoms of COVID-19 will last a long time (timeline belief) was predictive of adherence to handwashing only for those who believed they had not had COVID-19 $\left(\Delta R_{\text {interaction }}^{2}=.0028, F(1,2,543)=7.15\right.$, $p<.01$; unstandardized simple slope for COVID negatives $=.08(p<.001)$; unstandardized simple slope for COVID positives $=.01$ (n.s.)). Similarly, two causal beliefs were only predictive of adherence for those who believed they had not had COVID-19, namely, the belief that COVID is caused by my not wearing a face covering $\left(\Delta R_{\text {interaction }}^{2}=.0056, F\right.$ $(1,2,790)=16.12, p<.001 ;$ unstandardized simple slope for COVID negatives $=.08$ $(p<.001)$; unstandardized simple slope for COVID positives $=-.02$ (n.s.)) and the belief that COVID-19 is caused by other people not keeping $2 \mathrm{~m}$ distance $\left(\Delta R_{\text {interaction }}^{2}=.0074\right.$, 
Table 3. Summary of the moderation analyses

\begin{tabular}{|c|c|c|}
\hline TRB & Predictive construct & Moderation summary \\
\hline \multicolumn{3}{|c|}{ Beliefs about the behaviour: SCT/RAA } \\
\hline \multicolumn{3}{|c|}{ Moderator: None } \\
\hline \multicolumn{3}{|c|}{ Beliefs about illness: CS-SRM } \\
\hline \multicolumn{3}{|c|}{ Moderator: Perceived COVID-I 9 status } \\
\hline Physical distancing & $\begin{array}{l}\text { Cause (other people not keeping } \\
2 \mathrm{~m} \text { distance) }\end{array}$ & $\begin{array}{l}\text { Predicts only for those who } \\
\text { believe they have had covid- } 19\end{array}$ \\
\hline Handwashing & Timeline (duration) & Predict only for those who \\
\hline & $\begin{array}{l}\text { Cause (my not wearing a face } \\
\text { covering) }\end{array}$ & $\begin{array}{l}\text { believe they have not had } \\
\text { covid-19 }\end{array}$ \\
\hline & $\begin{array}{l}\text { Cause (other people not keeping } \\
2 m \text { distance) }\end{array}$ & \\
\hline Face covering & $\begin{array}{l}\text { Emotional representation } \\
\text { (worry) }\end{array}$ & $\begin{array}{r}\text { Stronger predictor for those who } \\
\text { believe they have had covid- } 19\end{array}$ \\
\hline \multicolumn{3}{|l|}{ Beliefs about Risk: PMT } \\
\hline \multicolumn{3}{|l|}{ Moderator: Sex } \\
\hline Handwashing & Response efficacy & Predicts for males only \\
\hline
\end{tabular}

$F(1,2,842)=21.61, p<.001 ;$ unstandardized simple slope for COVID negatives $=.08$ $(p<.001)$; unstandardized simple slope for COVID positives $=-.00$ (n.s.)).

\section{Beliefs about risk: PMT}

Perceived severity, response efficacy, and response self-efficacy were predictive of all three TRBs. However, only the relationship between response efficacy and handwashing was moderated, and by one sociodemographic factor only, namely gender $\left(\Delta R_{\text {interaction }}^{2}=.0070, F(1,2,445)=18.11, p<.001\right)$. Response efficacy predicted adherence for males but not for females (unstandardized simple slope for males $=.11$ $(p<.001)$, unstandardized simple slope for females $=.02(p=.11)$. Men who believed more strongly that the TRBs (following government instructions of keeping $2 \mathrm{~m}$ distance, wearing a face covering and washing their hands thoroughly and frequently) would be ineffective were less likely to wash their hands thoroughly and frequently.

\section{Discussion}

Overall, adherence to the three TRBs was high, confirming the findings from other studies (Coroiu et al., 2020; Park et al., 2020). Physical distancing and handwashing were high throughout and wearing a face covering increased following government recommendations and regulations. Nevertheless, given the seriousness of this pandemic, it is important to gain further understanding of how people who were less adherent differed from those with high adherence.

Various socio-demographic variables were associated with adherence. Given the greater risk to COVID-19 of older people (Driscoll et al., 2020), it is reassuring to find that they were more adherent to each of the three groups of TRBs. This might be due to their worry about the risk of getting the disease, their beliefs about the nature of the disease or how they think about the TRBs per se. It is possible that older people may simply find it 
easier to adhere to TRBs because they have reduced regular demands if they are retired from full-time working or have no child-care commitments. Further evidence of the importance of life context is the finding that handwashing adherence is greater in households with children, perhaps due to being additionally protective or being role models for their children. COVID-19 status was only directly associated with physical distancing: those who believed they had not had COVID-19 were more adherent to maintaining $2 \mathrm{~m}$ distance.

While sociodemographic factors are valuable in identifying who is less adherent and might therefore be a target for interventions to enhance adherence, they do not in themselves explain how or why the person is less adherent. Intervention design depends on understanding and attempting to change the course of the behavioural processes leading to the behaviour. The theories explored help to pinpoint key constructs associated with the TRBs which might be targeted as the mechanisms of action for a proposed intervention.

All three of the theories investigated were predictive of each of the TRBs. Using PMT, all variables were retained in the multivariable prediction, but response self-efficacy, the belief that one can carry out the TRBs likely to be effective, was strongest for each TRB. For the CS-SRM, timeline and cause variables were predictive for each TRB. Believing COVID19 to be recurring predicted each behaviour, while duration added to the predictive model for face coverings and handwashing. Causal factors were included in the models for each behaviour. Adherence to each TRB was greater if people believed COVID-19 was caused by other people not keeping their distance and for face covering and handwashing if they attributed the disease to their own behaviours. The pattern of results for the SCT/ RAA models was highly consistent across TRBs in showing both self-efficacy and intention to be retained in the final model for each behaviour.

The SCT/RAA model accounted for most variance for each behaviour, suggesting that beliefs about the behaviours, in each case self-efficacy and intention, were more important than beliefs about the disease or the risk of the disease. Since self-efficacy is theorised to be a determinant of intention, these findings emphasise the importance of self-efficacy. This is further confirmed in the PMT models where response self-efficacy has greater weighting than the beliefs about the risk or the effectiveness of the response. These findings are supported by other studies that have shown efficacy beliefs to predict adherence to TRBs during the pandemic (Chong et al., 2020; Jørgensen, Bor, \& Petersen, 2020). Few studies have examined the role of risk perceptions, illness cognitions, and efficacy beliefs within the same study. However, those that have done so, demonstrate self-efficacy to be a stronger predictor of adherence to TRBs than either illness perceptions or perceptions of risk or threat (Chong et al., 2020). Chong's study, which assessed the role of illness perceptions, coping, and self-efficacy on adherence during the first weeks of the second wave of the pandemic, indicated that the relationship between illness perceptions, (which in their study also contained perceptions of susceptibility and severity), and adherence was partly mediated by self-efficacy. Importantly, more negative illness perceptions were associated with lower self-efficacy and stronger self-efficacy was associated with higher adherence. Careful consideration, therefore, should be given to the likely impact of risk-based information on self-efficacy. We and others have shown selfefficacy to be a significant and consistent predictor of TRBs. Further, other studies have found self-efficacy to be predictive of positive mental health during the pandemic (Yıldırım \& Güler, 2020). Self-efficacy, therefore, may have an important role in protecting both physical and mental health. 
The moderation analyses examined how beliefs predicting adherence might differ in different socio-demographic groups. The relationships between self-efficacy and intention beliefs and adherence were not influenced by group, defined by gender, age, deprivation, household, and perceived COVID-19 status. This was found for each TRB and further confirmed for response self-efficacy. In the PMT analyses, there was some evidence that men were less likely to be adherent if they believed the TRB to be ineffective, suggesting that women were more likely to be adherent for other reasons than belief in the effectiveness of the action. This observation of greater adherence in women is consistent with other studies of adherence to TRBs during the current and previous pandemics (Bish \& Michie, 2010; Coroiu et al., 2020; Jørgensen et al., 2020).

As noted above, COVID-19 status per se was not directly predictive of adherence to any of the TRBs. However, it did moderate how beliefs about the illness predicted adherence. People holding some beliefs were more adherent if they believed they had not had COVID19 than if they had. This was found for the belief that the illness was caused by other people's behaviour for physical distancing and handwashing, the belief that the illness lasted a long time for handwashing, the belief that the illness was caused by not wearing a face covering for handwashing and the belief that the illness was worrying for face covering. It would appear that believing the illness was caused by behaviour of self and others, as well as beliefs that it was worrying and of long duration, had more impact on adherence to TRBs for those who had not had COVID-19.

Of the three theoretical models, the SCT/RAA model performed better than the others in predicting TRBs. To date, studies examining factors that predict adherence to TRBs have tended to focus on a single theoretical approach. As in previous pandemics (Bish \& Michie, 2010), the predictive utility of risk and threat perceptions is perhaps assessed most frequently (Plohl \& Musil, 2020; Wise et al., 2020; Yıldırım, Geçer, \& Akgül, 2020). That said, even using the other models, beliefs about behaviours, in managing risk in PMT and in causing the illness in CS-SRM, were important predictors of the TRBs. This may be due to uniformity of beliefs about the seriousness of the illness and the risks involved but point to the centrality of beliefs about the behaviours, rather than the illness, as key to understanding and potentially changing the behaviours. It further confirms the work done in the 1960 s by Fishbein that attitudes, such as attitudes to religion or race, were not so important in predicting behaviour as attitudes to behaviours, such as going to church or marrying someone from another race (Fishbein, 1965). Even as early as the 1960s, Leventhal had shown that enabling the person to actually enact behaviour might be as important as making them wish to perform it (Leventhal, Watts, \& Pagano, 1967).

The two consistent predictors of behaviour, self-efficacy and intention, might be proposed as mechanisms of action in designing interventions to enhance adherence (but see limitations). Bandura recommends four methods of enhancing self-efficacy and others have reviewed the effectiveness of various methods (Ashford, Edmunds, \& French, 2010). Based on triangulation of evidence from published interventions and from expert consensus, the Theory and Techniques online tool provides aggregated evidence of the likely effectiveness of over 60 behaviour change techniques in changing behaviour by each of these potential mechanisms of action (Dixon \& Johnston, 2020). Further work might be informed by the COM-B model to identify whether these mechanisms of action are more influenced by capability, opportunity or motivation (Michie, van Stralen, \& West, 2011) or using the MAP model of routes to behaviour change to identify action regulation or prompts and cues as the most promising approaches to intervention (Dixon \& Johnston, 2020). 
There are of course many caveats to these suggestions. These results are based on selfreports in a series of cross-sectional surveys. While there were important practical and policy reasons for designing the studies in this way, it is important to bear in mind that analyses of concurrent self-report data may find spuriously high relationships as they are inflated by the many forms of reporting bias. Nevertheless, the observed differences in these relationships between TRBs and between theoretical models are not subject to these biases. While the study reports the changes in the TRBs over the six waves of data collection, the relationships between variables are based on cross-sectional data obtained on the same occasion and are therefore limited in exploring relationships over time or causality. Thus, while it is not possible to conclude that self-efficacy caused the TRBs and might, as a result, be a suitable candidate for intervention as discussed above, it is possible to rule out some beliefs as important causes of (non)adherence to TRBs as they do not differentiate adherers from non-adherers. Studies with repeated measures from the same respondents in which beliefs are assessed at an earlier date than the subsequent behaviours give rather more credence to causality (Lin et al., 2020), and the CHARIS project is collecting such data at later stages (den Daas, Hubbard, Johnston, \& Dixon, 2020).

The strengths of CHARIS are its inclusivity and representativeness of a national population and in using a range of theories. By conducting the surveys by telephone rather than requiring respondents to have additional technology, the study did not exclude persons and groups such as older or deprived people (Kearns \& Whitley, 2019) who might lack such technology and who might also be particularly at risk of COVID-19 (Esai Selvan, 2020; Hawkins, Charles, \& Mehaffey, 2020). Reflecting the whole population, without any discriminating process allows the study to characterise the full range of socio-economic and geographical citizens of the country. Theories were selected to represent the current common and successful approaches to understanding behaviours in the context of illness. Despite the constraints of telephone interviewing, it was possible to gain information on an appropriate range of the proximal predictors from each of the three models and therefore to test not just single variables, but the combination of variables hypothesised to act together in determining behaviours.

Reports of the CHARIS project have been made available to national government departments on a regular basis and have therefore been available to those conducting modelling of COVID-19 and advising decision makers (https://www.abdn.ac.uk/iahs/re search/health-psychology/charis.php). Since the control of COVID-19 is primarily determined by population behaviour change, ensuring that government has such data are important. Even though effective vaccines are available, it remains important to investigate the role of behavioural factors both in adherence to TRBs during the immunization programme and in the uptake of the vaccine as hesitancy towards uptake of vaccines is an increasing problem (de Figueiredo, Simas, Karafillakis, Paterson, \& Larson, 2020; Larson, Jarrett, Eckersberger, Smith, \& Paterson, 2014). Unless such evidence in available to government, policy is likely to be guided by implicit, intuitive, lay models of behaviour change, often guided by the belief that education, fear-arousal, and instruction are enough, when there is extensive evidence demonstrating that information and motivation are not enough to enable behaviour change (Kelly \& Barker, 2016). Nevertheless, these behavioural factors need to be embedded in their social and policy contexts and the current work only addresses this in a limited way. 


\section{Acknowledgements}

We would like to thank our co-investigators on the CHARIS study: University of Aberdeen: Professor Peter Murchie and Dr Julia Allan; University of Stirling: Ms Martine Stead, Professor Ronan O'Carroll, Dr Barbara Farquharson, and Dr Wendy Maltinsky; University of Edinburgh: Professor Stewart Mercer; University of Strathclyde: Dr Leanne Fleming, and a Scotland-wide consortium of 33 behavioural scientists and our PPI Group. CHARIS was funded via a grant from the Chief Scientist Office, Edinburgh (COV/ABN/20/07).

\section{Conflicts of interest}

All authors declare no conflict of interest.

\section{Author contribution}

Diane Dixon, Ph.D. (Conceptualization; Funding acquisition; Methodology; Project administration; Writing - original draft; Writing - review \& editing) Chantal Den Daas (Conceptualization; Data curation; Formal analysis; Funding acquisition; Methodology; Writing - review \& editing) Gill Hubbard (Conceptualization; Funding acquisition; Methodology; Writing - review \& editing) Marie Johnston (Conceptualization; Funding acquisition; Methodology; Writing - review \& editing).

\section{Data availability statement}

The data that support the findings of this study are available from the corresponding author upon reasonable request.

\section{References}

Aiken, L. S., West, S. G., \& Reno, R. R. (1991). Multiple regression: Testing and interpreting interactions. London, UK: Sage.

Alagoz, O., Sethi, A., Patterson, B., Churpek, M., \& Safdar, N. (2020). Impact of timing of and adherence to social distancing measures on Covid-19 burden in the US: A simulation modeling approach. medRxiv. https://doi.org/10.1101/2020.06.07.20124859

Ashford, S., Edmunds, J., \& French, D. P. (2010). What is the best way to change self-efficacy to promote lifestyle and recreational physical activity? A systematic review with meta-analysis. British Journal of Health Psychology, 15, 265-288. https://doi.org/10.1348/ $135910709 \times 461752$

Azjen, I., \& Schmidt, P. (2020). Changing behavior using the theory of planned behavior. In M. S. Hagger, L. D. Cameron, K. Hamilton, N. Hankonen \& T. Lintunen (Eds.), The bandbook of behavior change (pp. 17-31). Cambridge, UK: Cambridge University Press.

Bandura, A. (Ed.). (1986). Social foundations of thought and action. Englewood Cliffs, NJ: PrenticeHall.

Bandura, A. (2001). Social cognitive theory: An agentic perspective. Annual Review of Psychology, 52, 1-26. https://doi.org/10.1146/annurev.psych.52.1.1

Bashirian, S., Jenabi, E., Khazaei, S., Barati, M., Karimi-Shahanjarini, A., Zareian, S., ... Moeini, B. (2020). Factors associated with preventive behaviours of COVID-19 among hospital staff in Iran in 2020: An application of the Protection Motivation Theory. The Journal of Hospital Infection, 105, 430-433. https://doi.org/10.1016/j.jhin.2020.04.035 
Belot, M., Choi, S., Jamison, J., Papageorge, N., Tripodi, E., \& van den Broek-Altenburg, E. (2020). Sixcountry survey on Covid-19. Retrieved from osf.io/aubkc.

Bish, A., \& Michie, S. (2010). Demographic and attitudinal determinants of protective behaviours during a pandemic: A review. The British Journal of Health Psychology, 15, 797-824. https:// doi.org/10.1348/135910710x485826

Bodas, M., \& Peleg, K. (2020). Self-isolation compliance in the Covid-19 era influenced by compensation: Findings from a recent survey in Israel. Health Affairs, 39, 936-941. https://doi. org/10.1377/hlthaff.2020.00382

Bogg, T., \& Milad, E. (2020). Slowing the spread of COVID-19: Demographic, personality, and social cognition predictors of guideline adberence in a representative U.S. Sample. doi: https://doi.org/10.31234/osf.io/yc2gq

Borthwick, C., O'Connor, R., \& Kennedy, L. (2020). Psychological predictors of seasonal influenza vaccination uptake among adults with a high-risk physical health condition: A systematic review. Psychology \& Health, 36, 214-235. https://doi.org/10.1080/08870446.2020.1772971

Bourassa, K. J., Sbarra, D. A., Caspi, A., \& Moffitt, T. E. (2020). Social Distancing as a health behavior: County-level movement in the united states during the Covid-19 pandemic is associated with conventional health behaviors. Annals of Behavioral Medicine, 54, 548-556. https://doi.org/ 10.1093/abm/kaaa049

Cameron, L. D., Fleszar-Pavlovic, S., \& Khachikian, T. (2020). Changing behavior using the CommonSense Model of Self-Regulation. In M. S. Hagger, L. D. Cameron, K. Hamilton, N. Hankonen \& T. Lintunen (Eds.), The handbook of behavior change (pp. 60-76). Cambridge, UK: Cambridge University Press.

Carvalho, L., \& Machado, G. (2020). Differences in adherence to COVID-19 pandemic containment measures: Psychopathy traits, empathy, and sex. Trends Psychiatry and Psychotherapy, 2, 389-392. https://doi.org/10.1590/2237-6089-2020-0055

Chong, Y. Y., Chien, W. T., Cheng, H. Y., Chow, K. M., Kassianos, A. P., Karekla, M., \& Gloster, A. (2020). The role of illness perceptions, coping, and self-efficacy on adherence to precautionary measures for Covid-19. International Journal of Environmental Research and Public Health, 17, 6540. https://doi.org/10.3390/ijerph17186540

Corace, K. M., Srigley, J. A., Hargadon, D. P., Yu, D., MacDonald, T. K., Fabrigar, L. R., \& Garber, G. E. (2016). Using behavior change frameworks to improve healthcare worker influenza vaccination rates: A systematic review. Vaccine, 34,3235-3242. https://doi.org/10.1016/j.vaccine.2016.04. 071

Coroiu, A., Moran, C., Campbell, T., \& Geller, A. (2020). Barriers and facilitators of adberence to social distancing recommendations among a large international sample of adults recruited in April 2020. OSFPREPRINTS (May 11). doi: https://doi.org/10.31219/osf.io/62g7z

de Figueiredo, A., Simas, C., Karafillakis, E., Paterson, P., \& Larson, H. J. (2020). Mapping global trends in vaccine confidence and investigating barriers to vaccine uptake: A large-scale retrospective temporal modelling study. The Lancet, 396, 898-908. https://doi.org/10.1016/ S0140-6736(20)31558-0

den Daas, C., Hubbard, G., Johnston, M., \& Dixon, D. (2020). Protocol CHARIS Study. doi: https:// doi.org/10.31234/osf.io/jnxcu

Dixon, D., \& Johnston, M. (2020). MAP: A mnemonic for mapping BCTs to three routes to behaviour change. British Journal of Health Psychology, 25, 1086-1101. https://doi.org/10.1111/bjhp. 12458

Driscoll, M., Ribeiro Dos Santos, G., Wang, L., Cummings, D. A. T., Azman, A. S., Paireau, J., . . Salje, H. (2020). Age-specific mortality and immunity patterns of SARS-CoV-2. Nature, 590, 140-145. https://doi.org/10.1038/s41586-020-2918-0

Duffy, B. (2020). Life under lockdown: Coronavirus in the UK. Retrieved from https://www.kcl.ac. uk/policy-institute/assets/coronavirus-in-the-uk.pdf

Esai Selvan, M. (2020). Risk factors for death from COVID-19. Nature Reviews Immunology, 20, 407. https://doi.org/10.1038/s41577-020-0351-0 
Faasse, K., \& Newby, J. M. (2020). Public perceptions of COVID-19 in Australia: Perceived risk, knowledge, health-protective behaviours, and vaccine intentions. medRxiv. https://doi.org/10. $1101 / 2020.04 .25 .20079996$

Fancourt, D., Bu, F., Wan Mak, H., \& Steptoe, A. (2020). Covid Social Study: Results Release 1. London. Retrieved from: https://746a1e8d-7231-4b96-9bc2-88b2eb5c4964.filesusr.com/ugd/ 3d9db5_a82c3a15441f4687a0114efc78307e80.pdf

Ferguson, N., Laydon, D., \& Nedjati-Gilani, G. (2020). Impact of non-pharmaceutical interventions (NPIs) to reduce COVID-19 mortality and healthcare demand. Retrieved from https://www. imperial.ac.uk/mrc-global-infectious-disease-analysis/Covid-19/report-9-impact-of-npis-onCovid-19/

Fishbein, M. (1965). A consideration of beliefs, attitudes, and their relationship. In I. D. Steiner \& M. Fishbein (Eds.), Current studies in social psychology (p. 10120). New York, NY: Holt Rinehart and Winston Inc.

Fishbein, M., \& Ajzen, I. (2011). Predicting and changing behavior: The reasoned action approach. New York, NY: Taylor \& Francis.

Freeman, D., Waite, F., Rosebrock, L., Petit, A., Causier, C., East, A., . . Lambe, S. (2020). Coronavirus conspiracy beliefs, mistrust, and compliance with government guidelines in England. Psychological Medicine, 1-13. https://doi.org/10.1017/s0033291720001890

Gibson Miller, J., Hartman, T. K., Levita, L., Martinez, A. P., Mason, L., McBride, O., . . Bentall, R. P. (2020). Capability, opportunity, and motivation to enact hygienic practices in the early stages of the COVID-19 outbreak in the United Kingdom. The British Journal of Health Psychology, 25, 856-864. https://doi.org/10.1111/bjhp.12426

Haque, A., Karim, W., Kabir, S. M. H., \& Tarofder, A. K. (2020). Understanding Social Distancing Intention among university students during Covid-19 outbreak: An application of protection motivation theory. Test Engineering and Management, 83, 16360-16377.

Harper, C. A., Satchell, L. P., Fido, D., \& Latzman, R. D. (2020). Functional fear predicts public health compliance in the Covid-19 pandemic. International Journal of Mental Health and Addiction. https://doi.org/10.1007/s11469-020-00281-5

Hawkins, R. B., Charles, E. J., \& Mehaffey, J. H. (2020). Socio-economic status and COVID-19-related cases and fatalities. Public Health, 189, 129-134. https://doi.org/10.1016/j.puhe.2020.09.016

Hayes, A. F. (2017). Introduction to mediation, moderation, and conditional process analysis: $A$ regression-based approach. New York, NY: Guilford Press.

Ipsos Mori. (2020). Face masks becoming normal but a flashpoint while 'COVID-secure' behaviours sticking. Retrieved from https://www.ipsos.com/ipsos-mori/en-uk/face-masks-bec oming-normal-flashpoint-while-Covid-secure-behaviours-sticking

Islam, N., Sharp, S. J., Chowell, G., Shabnam, S., Kawachi, I., Lacey, B., . . White, M. (2020). Physical distancing interventions and incidence of coronavirus disease 2019: Natural experiment in 149 countries. BMJ, 370, m2743. https://doi.org/10.1136/bmj.m2743

Jewell, N. P., Lewnard, J. A., \& Jewell, B. L. (2020). Predictive mathematical models of the Covid-19 pandemic: Underlying principles and value of projections. JAMA, 323, 1893-1894. https://doi. org/10.1001/jama.2020.6585

Johnston, M. (2015). Use and usability: Are theoretical models of behaviour change practical? In S. Christmas, S. Michie \& R. West (Eds.), Thinking about behaviour change: An interdisciplinary dialogue (pp. 68-83). London, UK: Silverback Publishing.

Jørgensen, F. J., Bor, A., \& Petersen, M. (2020). Compliance without fear: Individual-level predictors of protective behavior during the first wave of the Covid-19 pandemic. https://doi. org/10.31234/osf.io/uzwgf

Kearns, A., \& Whitley, E. (2019). Associations of internet access with social integration, wellbeing and physical activity among adults in deprived communities: Evidence from a household survey. BMC Public Health, 19(1), 860. https://doi.org/10.1186/s12889-019-7199-x

Kelly, M. P., \& Barker, M. (2016). Why is changing health-related behaviour so difficult? Public Health, 136, 109-116. https://doi.org/10.1016/j.puhe.2016.03.030 
Kirby, T. (2021). New variant of SARS-CoV-2 in UK causes surge of COVID-19. The Lancet Respiratory Medicine, 9, e20-e21. https://doi.org/10.1016/S2213-2600(21)00005-9

Larson, H. J., Jarrett, C., Eckersberger, E., Smith, D. M. D., \& Paterson, P. (2014). Understanding vaccine hesitancy around vaccines and vaccination from a global perspective: A systematic review of published literature, 2007-2012. Vaccine, 32, 2150-2159. https://doi.org/10.1016/j. vaccine.2014.01.081

Leventhal, H., Meyer, D., Nerenz, D., \& Rachman, S. (Eds.). (1980). The common sense representation of illness danger (Vol. 17). New York, NY: Pergamon Press.

Leventhal, H., Nerenz, D. R., \& Steele, D. S. (1984). Illness representations and coping with health threats. In A. Baum, S. E. Taylor, \& J. E. Singer (Eds.), Handbook of psychology and health (Vol. $I V$, pp. 219-252). Hillsdale, NJ: Erlbaum.

Leventhal, H., Watts, J., \& Pagano, F. (1967). Effects of fear and instructions on how to cope with danger. Journal of Personality and Social Psychology, 6, 313-321. https://doi.org/10.1037/ h0021222

Lin, C.-Y., Imani, V., Majd, N. R., Ghasemi, Z., Griffiths, M. D., Hamilton, K., . . Pakpour, A. H. (2020). Using an integrated social cognition model to predict COVID-19 preventive behaviours. The British Journal of Health Psychology, 25, 981-1005. https://doi.org/10.1111/bjhp.12465

Lyu, W., \& Wehby, G. L. (2020). Comparison of estimated rates of coronavirus disease 2019 (Covid19) in border counties in Iowa without a stay-at-home order and border counties in Illinois with a stay-at-home order. JAMA Network Open, 3(5), e2011102. https://doi.org/10.1001/jamane tworkopen.2020.11102

Masters, N. B., Shih, S.-F., Bukoff, A., Akel, K. B., Kobayashi, L. C., Miller, A. L., .. Wagner, A. L. (2020). Social distancing in response to the novel coronavirus (COVID-19) in the United States. PLoS One, 15, e0239025. https://doi.org/10.1371/journal.pone.0239025

Michie, S., van Stralen, M. M., \& West, R. (2011). The behaviour change wheel: A new method for characterising and designing behaviour change interventions. Implementation Science, 6, 42. https://doi.org/10.1186/1748-5908-6-42

Michie, S., West, R., Rogers, M. B., Bonell, C., Rubin, G. J., \& Amlôt, R. (2020). Reducing SARS-CoV-2 transmission in the UK: A behavioural science approach to identifying options for increasing adherence to social distancing and shielding vulnerable people. The British Journal of Health Psychology, 25, 945-956. https://doi.org/10.1111/bjhp.12428

Orbell, S., Zahid, H., \& Henderson, C. (2020). Changing behavior using the Health Belief Model and Protection Motivation Theory. In M. S. Hagger, L. D. Cameron, K. Hamilton, N. Hankonen \& T. Lintunen (Eds.), The handbook of behavior change (pp. 46-59). Cambridge, UK: Cambridge University Press.

Papakosma, M. (2020). Emotional Distress, Pandemic COVID-19 Perceptions and Reactions in Samples of Swedish and Greek Population (Dissertation). Retrieved from http://urn.kb.se/re solve?urn=urn:nbn:se:umu:diva-172293

Park, C. L., Russell, B. S., Fendrich, M., Finkelstein-Fox, L., Hutchison, M., \& Becker, J. (2020). Americans' Covid-19 stress, coping, and adherence to CDC guidelines. Journal of General Internal Medicine, 35, 2296-2303. https://doi.org/10.1007/s11606-020-05898-9

Pedersen, M. J., \& Favero, N. (2020). Social distancing during the Covid-19 pandemic: Who are the present and future noncompliers? Public Administration Review, 80, 805-814. https://doi.org/ 10.1111/puar.13240

Plohl, N., \& Musil, B. (2020). Modeling compliance with COVID-19 prevention guidelines: The critical role of trust in science. Psychology, Health \& Medicine, 26, 1-12. https://doi.org/10. 1080/13548506.2020.1772988

Rogers, R. W. (1975). A protection motivation theory of fear appeals and attitude change1. The Journal of Psychology, 91(1), 93-114. https://doi.org/10.1080/00223980.1975.9915803

West, R., Michie, S., Rubin, G. J., \& Amlôt, R. (2020). Applying principles of behaviour change to reduce SARS-CoV-2 transmission. Nature Human Behaviour, 4, 451-459. https://doi.org/10. 1038/s41562-020-0887-9 
Wise, T., Zbozinek, T. D., Michelini, G., Hagan, C. C., \& Mobbs, D. (2020). Changes in risk perception and protective behavior during the first week of the COVID-19 pandemic in the United States. doi: https://doi.org/10.31234/osf.io/dz428

Yıldırım, M., Geçer, E., \& Akgül, Ö. (2020). The impacts of vulnerability, perceived risk, and fear on preventive behaviours against COVID-19. Psychology, Health \& Medicine, 26(1), 35-43. https://doi.org/10.1080/13548506.2020.1776891

Yıldırım, M., \& Güler, A. (2020). COVID-19 severity, self-efficacy, knowledge, preventive behaviors, and mental health in Turkey. Death Studies, 1-8. https://doi.org/10.1080/07481187.2020. 1793434

YouGov. (2020). Personal measures taken to avoid Covid-19. Retrieved from https://yougov.co. uk/topics/international/articles-reports/2020/03/17/personal-measures-taken-avoid-Covid-19

Received 6 January 202 I; revised version received I6 April 202 I

\section{Supporting Information}

The following supporting information may be found in the online edition of the article: Supinfo S1 